\title{
Withaferin A inhibits pro-inflammatory cytokine-induced damage to islets in culture and following transplantation
}

\author{
J. A. SoRelle • T. Itoh • H. Peng • M. A. Kanak • \\ K. Sugimoto $\cdot$ S. Matsumoto $\cdot$ M. F. Levy $\cdot$ \\ M. C. Lawrence • B. Naziruddin
}

Received: 21 June 2012 / Accepted: 7 December 2012 / Published online: 15 January 2013

(C) Springer-Verlag Berlin Heidelberg 2013

\begin{abstract}
Aims/hypothesis Beta cell death triggered by pro-inflammatory cytokines plays a central role in the pathogenesis of type 1 diabetes and loss of transplanted islets. The nuclear factor $\kappa B(\mathrm{NF}-\mathrm{kB})$ signalling pathway is a key regulator of beta cell stress response, survival and apoptosis. Withaferin A (WA), a steroidal lactone derived from Withania somnifera, has been demonstrated to be a potent, safe, anti-inflammatory molecule that can inhibit NF- $\mathrm{kB}$ signalling. Therefore, we evaluated the ability of WA to protect mouse and human islets from the damaging effects of pro-inflammatory cytokines in vitro and following intraportal transplantation.

Methods Mouse and human islets were treated with a cytokine cocktail, and NF-kB activation was measured by immunoblots, p65 nuclear translocation and chromatin immunoprecipitation of p65-bound DNA. Intraportal transplantation of a marginal
\end{abstract}

Electronic supplementary material The online version of this article (doi:10.1007/s00125-012-2813-9) contains peer-reviewed but unedited supplementary material, which is available to authorised users.

J. A. SoRelle and T. Itoh contributed equally to this study.

J. A. SoRelle $\cdot$ H. Peng $\cdot$ M. A. Kanak

Institute of Biomedical Studies, Baylor University,

Waco, TX, USA

T. Itoh $\cdot$ K. Sugimoto $\cdot$ S. Matsumoto $\cdot$ M. C. Lawrence

Baylor Research Institute, Dallas, TX, USA

M. F. Levy $\cdot$ B. Naziruddin

Baylor University Medical Center, Dallas, TX, USA

M. F. Levy $\cdot$ B. Naziruddin $(\bowtie)$

Annette C. and Harold C. Simmons Transplant Institute,

Baylor University Medical Center at Dallas, 3410 Worth Street,

Dallas, TX 75246, USA

e-mail: bashoon@baylorhealth.edu mass of syngeneic mouse islets was performed to evaluate the in vivo protective effect of WA.

Results Treatment with WA substantially improved islet engraftment of syngeneic islets $(83 \%$ for infusion with 200 islets $+\mathrm{WA} ; 0 \%$ for 200 islets + vehicle) in a mouse model of diabetes, compared with marginal graft controls with superior islet function in WA-treated mice confirmed by glucose tolerance test. Treatment of human and mouse islets with WA prevented cytokine-induced cell death, inhibited inflammatory cytokine secretion and protected islet potency.

Conclusions WA was shown to be a strong inhibitor of the inflammatory response in islets, protecting against cytokineinduced cell damage while improving survival of transplanted islets. These results suggest that WA could be incorporated as an adjunctive treatment to improve islet transplant outcome.

Keywords Beta cell $\cdot$ Cytokine $\cdot$ Islet transplantation $\cdot \mathrm{NF}-\mathrm{kB}$

$\begin{array}{ll}\text { Abbreviations } \\ \text { G-CSF } & \text { Granulocyte-colony stimulating factor } \\ \text { IBMIR } & \text { Instant blood-mediated inflammatory response } \\ \text { I } \mathrm{B} \text { } & \text { Inhibitor of } \kappa \mathrm{B} \\ \text { IKK } \beta & \text { Inhibitor of } \kappa \text { B kinase beta } \\ \text { iNOS } & \text { Inducible nitric oxide synthase } \\ \text { IP-10 } & \text { IFN } \gamma \text {-induced protein 10 } \\ \text { IPGTT } & \text { Intraperitoneal glucose tolerance test } \\ \text { MCP-1 } & \text { Monocytic chemotactic protein-1 } \\ \text { MIG } & \text { Monokine induced by IFN- } \gamma \\ \text { MIP } & \text { Macrophage inflammatory protein } \\ \text { NEMO } & \text { NF- } \kappa \text { B essential modulator } \\ \text { NF } \kappa B & \text { Nuclear factor } \kappa B \\ \text { PI } & \text { Propidium iodide } \\ \text { RANTES } & \text { Regulated and normal T cell-expressed and se- } \\ & \text { creted chemokine }\end{array}$




$\begin{array}{ll}\text { STZ } & \text { Streptozotocin } \\ \text { TF } & \text { Tissue factor } \\ \text { WA } & \text { Withaferin A }\end{array}$

\section{Introduction}

Type 1 diabetes mellitus is an autoimmune disorder that leads to destruction of the insulin-producing beta cells of the pancreas. Islet cell transplantation to replace depleted beta cells has emerged as an effective treatment in recent years. However, a substantial number of islets are destroyed by the instant blood-mediated inflammatory response (IBMIR), cytokines, hypoxia-reoxygenation injury, apoptosis, factors related to isolation and other factors $[1,2]$. The blood-mediated nonspecific immune response is characterised by coagulation, complement activation, platelet aggregation and cytokine release [2]. Cytokines such as TNF- $\alpha$, IFN- $\gamma$ and IL-1 $\beta$ have important pro-inflammatory and proapoptotic roles in type 1 diabetes and islet transplantation [3-5]. Although immunosuppressants are administered after transplantation of islets, effective control of cytokinemediated damage to islets is still not achieved.

Inflammatory cytokines cause beta cell damage through a signal transduction pathway initiated at TNF and IL-1 receptors and mediated through a downstream signalling molecule, nuclear factor $\mathrm{KB}(\mathrm{NF}-\mathrm{kB})$. It has been shown that a cytokine cocktail of TNF- $\alpha$, IFN- $\gamma$, and IL- $1 \beta$ led to NF- $\mathrm{kB}$ activation in human islets [6]. A recent study examined the dual role of hypoxia and cytokines on NF-kB activation and proposed that cytokine-mediated NF- $\mathrm{kB}$ activation was modulated by different levels of hypoxia [7]. Pro-inflammatory cytokines have also been shown to upregulate mRNA of several chemokines in islets [8]. These chemokines act as chemoattractants for lymphocytes, directing them towards the site of transplantation. This has been observed with CCL2 (monocytic chemotactic protein-1 [MCP-1]) secretion, demonstrating macrophage infiltration of islet grafts leading to a negative clinical outcome $[9,10]$. In addition, pro-inflammatory cytokines promote beta cell damage by exacerbating cellular injury and death signalling pathways mediated by NF- $\mathrm{KB}$ in islets [10]. Since NF-KB is a cytokine-induced mediator of several inflammatory genes in beta cells, it provides an attractive therapeutic target for inhibition.

Withaferin A (WA), a naturally occurring plant-derived molecule, has been identified as a multifunctional, bioactive compound with strong anti-inflammatory, antioxidant and anti-angiogenic properties [11]. The origin of WA is from a plant species called Withania somnifera, which has been used for centuries in traditional eastern medicine with proven clinical safety $[12,13]$. There are several extracts from the leaves of $W$. somnifera, but a study by Kaileh et al identified the steroidal lactone, WA, as the most potent inhibitor of NF- $\mathrm{KB}$ based on the hyperphosphorylation of inhibitor of $\kappa B(\mathrm{I} \kappa \mathrm{B})$ kinase beta $(\mathrm{IKK} \beta)$ preventing I $\mathrm{K} B$ degradation [14]. Grover et al suggested that WA inhibits $N F-K B$ by preventing the formation of NF- $K B$ essential modulator (NEMO)/IKK $\beta$ complex [15]. WA has been studied as an anti-inflammatory compound in cystic fibrosis [16] with further potential to treat chronic inflammatory diseases such as rheumatoid arthritis, asthma and inflammatory bowel disease $[17,18]$.

The objective of this study was to demonstrate the protective effects of WA in preventing cytokine-induced damage to islets under in vivo and in vitro conditions. We have previously demonstrated that inflammatory cytokines cause dramatically increased levels of several inflammatory cytokines and chemokines (inducible nitric oxide synthase [iNOS], IL-1 $\beta$, regulated and normal $\mathrm{T}$ cell-expressed and secreted chemokine [RANTES], monokine induced by IFN- $\gamma$ [MIG] and IFN $\gamma$ induced protein 10 [IP-10]) in human islets as determined by quantitative PCR analysis [8]. WA was shown to decrease the mRNA levels of several of these chemokines by tenfold or more. This led to further investigation of the role of WA as pharmacological modulator of the early inflammatory reaction in an in vivo mouse model. Inclusion of human pancreatic islets in this study allowed us to determine whether the results from the mice data can be translated to a clinical setting.

\section{Methods}

Human islet isolation Human-research-grade pancreases were used for isolating islets using methods described previously [19-21]. Human islets used in this study were handpicked to greater than $95 \%$ purity. Islets were cultured with Connaught Medical Research Laboratories (CMRL)based human islet culture media containing $0.1 \%$ BSA with kanamycin $\left(37^{\circ} \mathrm{C}, 5 \% \mathrm{CO}_{2}\right.$ up to $\left.96 \mathrm{~h}\right)$. These experiments were approved by the Institutional Review Board at Baylor Research Institute (BRI), Dallas, TX, USA.

Mouse islet isolation Islets were isolated from male inbred C57BL/6N mice (Harlan Labs, Houston, TX, USA) using a previously described procedure [22, 23]. Islets were cultured at a purity greater than $95 \%$ in DMEM supplemented with kanamycin and $0.1 \% \mathrm{BSA}\left(37^{\circ} \mathrm{C}, 5 \% \mathrm{CO}_{2}\right.$ up to $\left.96 \mathrm{~h}\right)$.

Intraportal transplantation Diabetes was induced in the mouse models by injecting streptozotocin (STZ; $180 \mathrm{mg} /$ $\mathrm{kg}$ ) intravenously. Mice were considered diabetic when their blood glucose was greater than $19.5 \mathrm{mmol} / \mathrm{l}$ for two consecutive days. Two-hundred islets were injected into the portal vein by puncturing the hepatic portal vein [22]. WA $(1.25 \mathrm{mg} / \mathrm{kg}$ body weight) or vehicle (Dulbecco's phosphate-buffered saline [DPBS]) was injected into the 
peritoneal cavity. These experiments were approved by the Institutional Animal Care and Use Committee at BRI.

Intraperitoneal glucose tolerance test Naive, transplanted and STZ-induced diabetic mice were used to perform an intraperitoneal glucose tolerance test (IPGTT) [22]. The mouse's food was removed for 12-14 h, then an injection of glucose $(1 \mathrm{~g} / \mathrm{kg})$ was administered intraperitoneally. Blood glucose was monitored with Accu-Chek (Roche Diagnostics, Indianapolis, IN, USA) at 0, 30 and $120 \mathrm{~min}$ after the injection.

Cytokine and WA treatment After isolation and overnight culture, islets were subjected to inflammatory conditions in vitro with a cytokine cocktail of the species-specific recombinant proteins $(1,000 \mathrm{U} / \mathrm{ml}$ TNF- $\alpha, 1,000 \mathrm{U} / \mathrm{ml} \mathrm{IFN}-\gamma$ and $50 \mathrm{U} / \mathrm{ml} \mathrm{IL}-1 \beta)[24,25]$. Islets were treated with WA at concentrations in the range $0.25-2.0 \mu \mathrm{g} / \mathrm{ml}$. All islets were cultured in a humidified incubation chamber at $37^{\circ} \mathrm{C}$ with $5 \%$ $\mathrm{CO}_{2}$ up to $96 \mathrm{~h}$. Viability was determined by Hoechst 33342/ propidium iodide (PI) staining. See the electronic supplementary material (ESM) Methods for detailed procedure.

Immunohistochemistry Islets and engrafted livers were fixed and stained as described previously and imaged via fluorescence microscopy (BX16 and DP-72; Olympus, Tokyo, Japan) [26]. Mean fluorescence intensity was calculated as the integrated density divided by the area in the insulin-positive region of interest.

TUNEL assay The TUNEL assay was performed with a ApopTag fluorescein in situ apoptosis detection kit (Millipore, Billerica, MA, USA) [22]. See ESM Methods for detailed procedure.

Measurement of secreted inflammatory cytokines and chemokines Fifty islets were cultured in quintuplet in islet culture media for $96 \mathrm{~h}$ with the cytokine and WA treatment. Pro-inflammatory cytokines in culture supernatant fractions were measured with a Luminex 200 system (Luminex, Austin, TX, USA) [9]. See ESM Methods for detailed procedure.

Western blotting After cytokine-treated cells were lysed, the proteins in the lysate were subjected to SDS-PAGE and transferred onto nitrocellulose membranes. The membranes were incubated with primary antibodies to IkB- $\alpha$ and ERK1/2, followed by secondary antibodies conjugated with fluorescent dyes. See ESM Methods for further detail.

Chromatin immunoprecipitation assay Chromatin DNAprotein was crosslinked in human islets $(5,000$ islet equivalents [IEQ]) or MIN6 cells $\left(5 \times 10^{7}\right)$ with $1 \%$ formaldehyde. See ESM Methods for detailed procedure.
Real-time PCR assay After human islets had been lysed by lysis buffer, RNA was purified using an Absolutely RNA Miniprep kit (Stratagene, La Jolla, CA, USA) and then reverse transcribed into cDNA. See ESM Methods for further detail.

p65 Translocation assay The NF-kB p65 nuclear localisation was determined by overlap of Alexa-594 labelled NFKB antibody and DAPI-stained nuclei with confocal laser scanning microscope (Leica Microsystems, Wetzlar, Germany). See ESM Methods for detailed procedure.

Neutrophil infiltration in purified human islets mixed with autologous blood A modified loop model was employed using human islets mixed with autologous human blood samples. See ESM Methods for detailed procedure.

Glucose-stimulated insulin secretion test Islets were incubated with low $(1.67 \mathrm{mmol} / \mathrm{l})$ and then high $(16.7 \mathrm{mmol} / \mathrm{l})$ concentrations of glucose solution. See ESM Methods for detailed procedure.

Reagents WA was purchased from Enzo Life Sciences (Plymouth Meeting, PA, USA). The recombinant human cytokines TNF- $\alpha\left(1.1 \times 10^{5} \mathrm{U} / \mu \mathrm{g}\right)$, IFN- $\gamma\left(2.0 \times 10^{4} \mathrm{U} / \mu \mathrm{g}\right)$ and IL-1 $\beta\left(2.0 \times 10^{5} \mathrm{U} / \mu \mathrm{g}\right)$ were purchased from R\&D Systems (Minneapolis, MN, USA). The recombinant mouse cytokines TNF- $\alpha\left(2.7 \times 10^{5} \mathrm{U} / \mu \mathrm{g}\right), \mathrm{IFN}-\gamma\left(8.43 \times 10^{3} \mathrm{U} / \mu \mathrm{g}\right)$ and IL-1 $\beta\left(1.1 \times 10^{6} \mathrm{U} / \mu \mathrm{g}\right)$ were also purchased from R\&D Systems.

Statistics The statistical significance between two groups was analysed by the Student's $t$ test. For statistical analysis among three groups or more, one-way ANOVA with TukeyKramer post hoc tests was performed using StatView 5.0 (SAS Institute, Cary, NC, USA) [27]. A significant difference was achieved when $p<0.05$.

\section{Results}

WA improves survival of intraportally transplanted mouse syngeneic islets To determine the anti-inflammatory effects of WA on in vivo islet transplantation, a syngeneic C57BL/6 mouse islet transplant model was used. Initial experiments determined that 400 islets were required to achieve normoglycaemia following intraportal infusion. Using only half that number of islets resulted in a $0 \%$ success rate, indicating that 200 islets alone were insufficient to reverse hyperglycaemia (Fig. 1a, b). Daily intraperitoneal injection of WA $(1.25 \mathrm{mg} / \mathrm{kg}$ body weight) for 7 days post-transplant beginning immediately after islet infusion led to normoglycaemia in $5 / 6$ mice $(83 \%)$ with infusion of a suboptimal dose of 200 islets 

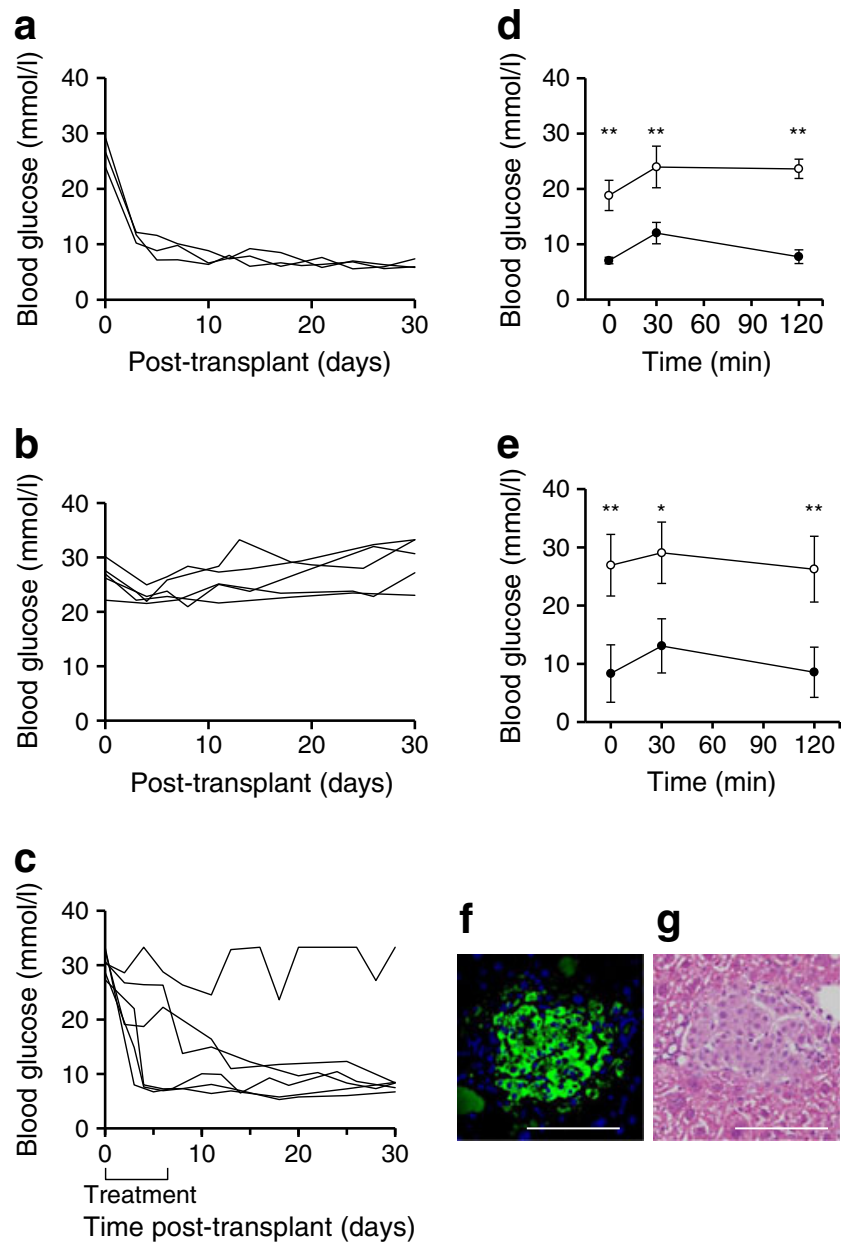

Fig. 1 Intraportal islet isograft survival is improved by WA administration as demonstrated by normoglycaemia, glucose tolerance test and histological evaluation. Intraportal transplantation of 400 islets into C57BL/6 mice had a success rate of 100\% (3/3) (a), but transplantation of 200 syngeneic islets with injection of $0.5 \mathrm{ml} \mathrm{PBS}$ (vehicle) resulted in $0 \%(0 / 5)$ of recipients achieving normoglycaemia (b). (c) Daily administration of WA $(1.25 \mathrm{mg} / \mathrm{kg}$ body weight $)$ starting immediately after transplantation and lasting 7 days yielded a much higher success rate of $83 \%(5 / 6)$. (d) IPGTT was performed to assess glycaemic control of naive (black circles) and STZ-induced diabetic mice (white circle) for comparison against (e) WA-treated (black circles) and vehicle-treated mice (white circles) on day 30 post-transplant. There was a significant difference in blood glucose levels at each time. Naive and WA-treated mice demonstrated a similar pattern with normalisation of blood glucose levels below $11.1 \mathrm{mmol} / 1$ after $120 \mathrm{~min}$. After 30 days, hepatectomy of recipient mice was performed and the liver was fixed in formalin, embedded in paraffin and stained for insulin (f) and with haematoxylin and eosin (g). Graphical representations are expressed as means \pm SD. ${ }^{*} p<0.005,{ }^{* *} p<0.0005$ as determined by Tukey-Kramer post hoc tests. Scale bar $50 \mu \mathrm{m}$

(Fig. 1c). The IPGTT test performed to assess islet function showed a significant difference between normal and STZtreated mice (Fig. 1d). A similar pattern was seen in the WA-treated mice, which showed a significant difference for each time point compared with the vehicle-treated mice (Fig. 1 e, $8.4 \pm 5.0$ vs $26.9 \pm 5.3 \mathrm{mmol} / 1$ glucose at $0 \mathrm{~min}$, $p<0.0005 ; 14.9 \pm 4.7$ vs $29.1 \pm 5.3 \mathrm{mmol} / 1$ glucose at $30 \mathrm{~min}$, $p<0.005 ; 8.7 \pm 4.5$ vs $26.3 \pm 5.7 \mathrm{mmol} / 1$ glucose at $120 \mathrm{~min}$, $p<0.0005)$. This data demonstrated that mice receiving WA post-transplant had a sufficient islet mass to be functional and comparable with naive mice. Immunohistochemical staining of the engrafted islets in the presence of WA showed functionally intact islets demonstrated by positive insulin stain and retention of the islet architecture (Fig. 1f, g).

WA prevents $N F-\kappa B$ translocation after intraportal transplantation WA has been reported to be a multifunctional molecule with an inhibitory action on NF- $\mathrm{KB}[11,14]$. Hence we evaluated the ability of WA to prevent NF- $k B$ activation post-transplant by analysing p 65 translocation in transplanted islets. Mice were transplanted with 200 syngeneic islets as described before and administered either vehicle or WA $(1.25 \mathrm{mg} / \mathrm{kg}$ body weight) intraperitoneally. Livers from mice ( $n=3$ per treatment) were removed $3 \mathrm{~h}$ post-transplant and stained for insulin and p65 (ESM Fig. 1). Islet sections were visualised with confocal microscopy. We observed that compared with vehicle-treated mice (ESM Fig. 1a-c), WA-treated mice (ESM Fig. 1d-f) had significantly decreased p65 nuclear localisation in islets (ESM Fig. 1g)

WA does not affect islet viability and function in vitro at low concentrations To determine its toxicity on islets, human $(n=3)$ and mouse $(n=6)$ islets were cultured in the presence of WA $(0.5-2.0 \mu \mathrm{g} / \mathrm{ml})$ and viability and function were tested. After $24 \mathrm{~h}$, human islets cultured with 0.5 and $1.0 \mu \mathrm{g} / \mathrm{ml}$ of WA showed no significant change in viability whereas $2.0 \mu \mathrm{g} / \mathrm{ml}$ WA caused a significant decrease (ESM Fig. 2a) compared with control islets ( $70.5 \pm 8.8 \%$ vs $94.9 \pm 4.5 \%, t$ test, $p<0.0001)$. After $48 \mathrm{~h}$, there was no noticeable difference between control (91.8 \pm $7.4 \%)$ and treatment with either $0.5 \mu \mathrm{g} / \mathrm{ml}(89.0 \pm 4.6 \%, p=0.36)$ or $1.0 \mu \mathrm{g} / \mathrm{ml} \mathrm{WA}(91.9 \pm 3.5 \%, p=0.87)$; furthermore, at $96 \mathrm{~h}$ there was no change with $0.5 \mu \mathrm{g} / \mathrm{ml}(97.7 \pm 0.8 \%, p>0.05)$ and $1.0 \mu \mathrm{g} / \mathrm{ml}$ WA $(95.9 \pm 2.6 \%, p>0.05)$ compared with control (93.5 $\pm 4.6 \%$ ). Concentrations of 0.25 and $0.5 \mu \mathrm{g} / \mathrm{ml} \mathrm{WA} \mathrm{caused}$ no significant decrease in viability of mouse islets (ESM Fig. 3a, b) whereas $1.0 \mu \mathrm{g} / \mathrm{ml}$ WA significantly decreased viability compared with control $(87.8 \pm 11.1 \%$ vs $97.3 \pm 2.2 \%$, $p<0.05$ ); this pattern was continued at $48 \mathrm{~h}$ and $96 \mathrm{~h}$. Furthermore, there was no significant difference in islet function as indicated by stimulation index (ESM Fig. 2b) between control human islets $(4.55 \pm 1.53)$ or islets cultured with $0.5(3.52 \pm 0.41, p=0.10)$ or $1.0 \mu \mathrm{g} / \mathrm{ml} \mathrm{WA}$ $(4.21 \pm 1.97, p=0.51)$ after $24 \mathrm{~h}$. Similarly, mouse islets showed no significant difference in stimulation index after $24 \mathrm{~h}$ between control $(11.13 \pm 9.28)$ and islets treated with $0.5 \mu \mathrm{g} / \mathrm{ml}$ WA $(7.05 \pm 2.20, p=0.30)$ (ESM Fig. $3 \mathrm{c}$ ). These results showed that WA at low concentrations did not affect islet viability and function. 
WA protects islets from cytokine-induced damage and preserves islet function We evaluated the effect of WA on islet cell viability and potency after exposure to cytokines. Cytokine cocktail significantly increased islet cell death at $24 \mathrm{~h}$ compared with control levels in human islets (viability: $85.8 \pm 3.9 \%$ vs $93.5 \pm 3.2 \%, p<0.05$; Fig. $2 \mathrm{a}$, b). WA prevented this damage at concentrations of $0.5(92.6 \pm 5.1 \%$ viability) and $1.0 \mu \mathrm{g} / \mathrm{ml}(94.6 \pm 2.9 \%)(p<0.05$ [vs cytokine] for both concentrations of WA), while there was no significant difference in viability between control islets and islets treated with WA alone $(p>0.05)$. After $48 \mathrm{~h}$ there was a significant difference in viability of the human islets seen between each treatment and cytokines. Viability of mouse islets was also significantly decreased by cytokines compared with control (viability: $78.1 \pm 11.6 \%$ vs $93.3 \pm$ $2.9 \%, p<0.05$; ESM Fig. $4 \mathrm{a}, \mathrm{b}$ ), and addition of WA to islets cultured with cytokines improved outcome. This pattern continued in mouse islets after $48 \mathrm{~h}$.

In addition, apoptosis in human islets was increased by cytokine treatment as demonstrated by increased TUNEL positive staining in beta cells. At $24 \mathrm{~h}$, there was a significant difference between each treatment group (Fig. 2c, d) except when comparing control vs treatment with cytokines plus $1.0 \mu \mathrm{g} / \mathrm{ml}$ WA. The TUNEL assay demonstrated that WA can effectively negate the effect of cytokines on beta cell apoptosis.

Evaluation of the ability of human islets to secrete insulin after $24 \mathrm{~h}$ revealed that cytokines significantly decreased the stimulation index compared with control $(1.36 \pm 0.34$ vs $1.83 \pm 0.15, p<0.05$; Fig. 2 e). However, $1.0 \mu \mathrm{g} / \mathrm{ml}$ WA significantly increased the stimulation index compared with cytokines alone $(2.20 \pm 0.61, p<0.05)$ and showed no significant difference compared with control islets $(p>0.05)$. Stimulation index values for mouse islets demonstrated a similar pattern (ESM Fig. 4c).

Fig. 2 WA protects human islets from inflammatory cytokinemediated cell death. (a, b) Human islets were incubated with the inflammatory cytokine cocktail (CYT) for 24 and $48 \mathrm{~h}$ with or without WA, and with WA alone. Islets were recovered and viability was assessed by Hoechst 33342/PI nuclear staining. (b) Black solid line with white circle, control; black dotted line with black circle, cytokine; red dotted line with white square, cytokine plus $0.5 \mu \mathrm{g} / \mathrm{ml} \mathrm{WA} \mathrm{(CYT+}$ $0.5 \mathrm{WA}$ ); red solid line with red square, cytokine plus $0.5 \mu \mathrm{g} / \mathrm{ml} \mathrm{WA}$ $(\mathrm{CYT}+1.0 \mathrm{WA})$; blue dotted line with white triangle, $0.5 \mu \mathrm{g} / \mathrm{ml} \mathrm{WA}$ (0.5WA); blue solid line with blue triangle $1.0 \mu \mathrm{g} / \mathrm{ml} \mathrm{WA} \mathrm{(1.0WA).} \mathrm{(c)}$ Cytokine-mediated beta cell apoptosis was confirmed by TUNEL staining. Human islets were stained for insulin (red) and apoptotic nuclei (green). (d) Manual counting of more than 250 nuclei revealed higher levels of apoptosis when islets were exposed to cytokines. This raised level was significantly reduced by the addition of WA, which returned apoptosis to control levels $(1.0 \mu \mathrm{g} / \mathrm{ml} \mathrm{WA})$. (e) Islet potency was assessed by static incubation after $24 \mathrm{~h}$. Results shown are representative of six independent human islet preparations. Graphical representations are expressed as means $\pm \mathrm{SD}$. $p<0.05$ compared with CYT as determined by Tukey-Kramer post hoc tests. Scale bar $=50 \mu \mathrm{m}$
WA prevents degradation of $I \kappa B$ and $N F-\kappa B$ association with DNA when human islets and beta cells are exposed to cytokines Inflammation elicited by immune cells requires the activation of NF- $\mathrm{KB}$ [28-30]. NF- $\mathrm{kB}$ is activated as a direct result of phosphorylation and rapid degradation of inhibitory I $k B$ protein $[31,32]$. To identify effects of cytokines on NF- $\mathrm{KB}$ signalling in islets, we analysed the effects of cytokine cocktail on IKB in human islets and beta cell lines (MIN6 and INS1). In response to cytokine cocktail,

a

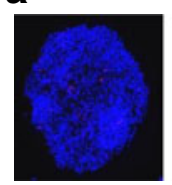

Control

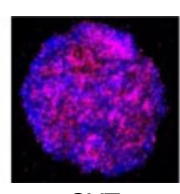

CYT

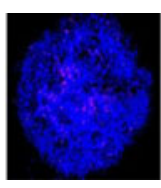

$\mathrm{CYT}+0.5 \mathrm{WA}$

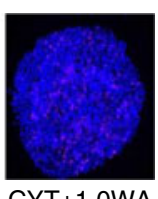

$\mathrm{CYT}+1.0 \mathrm{WA}$

b

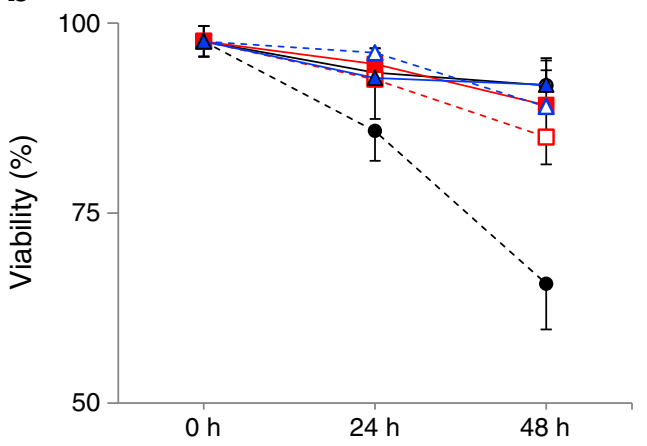

C

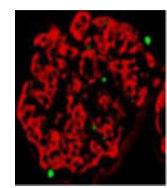

Control

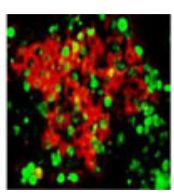

CYT

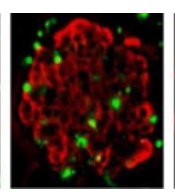

CYT+0.5WA

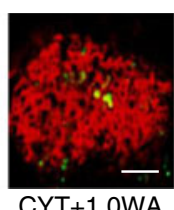

CYT+1.0WA

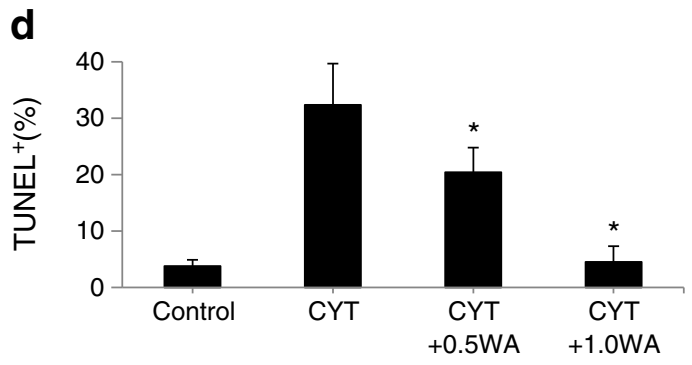

e

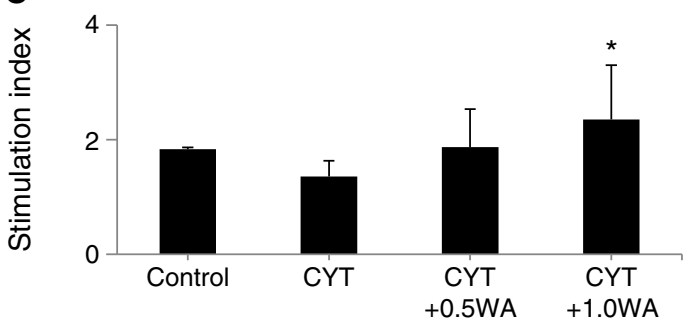


IKB was rapidly reduced (up to $90 \%$ ) relative to levels of extracellular-signal-regulated kinase 1/2 (ERK1/2) (Fig. 3a, b). In each case, WA prevented the reduction of $I \kappa B$, indicating that it inhibits NF- $\mathrm{KB}$ activation in human islets and beta cell lines. Furthermore, immunoblot analysis showed that WA increased ERK1/2 activation and had little effect on c-jun $\mathrm{N}$ terminal kinase and p38 (ESM Fig. 5). We evaluated DNA binding and NOS2 mRNA levels, a cytotoxic gene product of the NF- $\mathrm{KB}$ pathway encoding inducible nitric oxide synthase (iNOS). WA significantly inhibited both binding of NF- $\mathrm{KB}$ to the DNA promoter region for iNOS (Fig. 3c) and mRNA levels (Fig. 3d). These results showed that WA had an impact on NF-kB signalling.

$N F-\kappa B$ translocation in human beta cells is inhibited by $W A$ We evaluated NF- $\mathrm{KB}$ nuclear localisation at $24 \mathrm{~h}$ by immunohistochemical staining of the p65 subunit. All insulin-positive cells in human islets were counted and

a

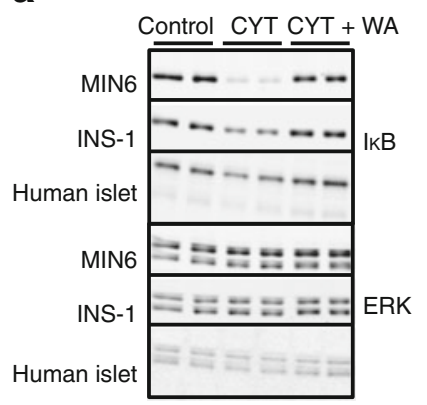

C

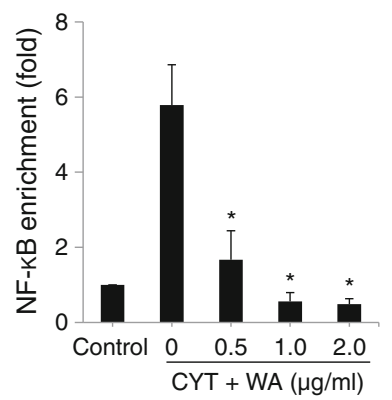

b

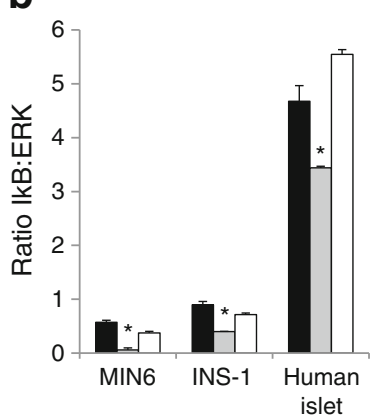

d

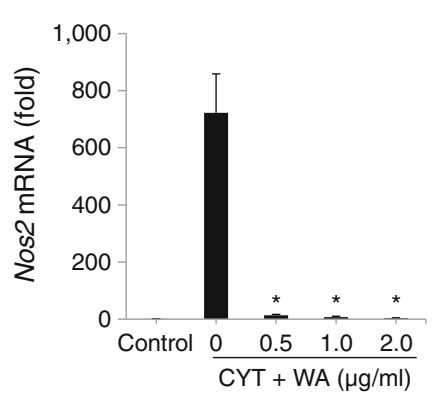

Fig. 3 WA prevents IKB degradation and subsequent association of NF$\kappa \mathrm{B}$ with iNOS promoter in human islets. (a) Immunoblot analysis of I $\mathrm{KB}$ protein in human islets and beta cell lines treated with a cytokine cocktail (CYT) for $20 \mathrm{~min}$ in the presence or absence of WA. Experiments were repeated three times and performed in duplicate. (b) Graphical representations are expressed as means $\pm \mathrm{SD}$. Black bar, control; grey bar, cytokine treated; white bar, cytokine plus $1 \mu \mathrm{g} / \mathrm{ml} \mathrm{WA} .{ }^{*} p<0.05$ compared with control. (c) Chromatin immunoprecipitation analysis of fold increase vs control NF- $\mathrm{KB}$ associated with the iNOS promoter in human islets treated with CYT for $30 \mathrm{~min}$. Cells were pretreated with $0-2 \mu \mathrm{g} / \mathrm{ml} \mathrm{WA}$. ${ }^{*} p<0.05$ compared with CYT. (d) mRNA levels (fold vs control) of NOS2 in human islets treated under the same conditions were analysed with quantitative PCR standardised to control levels. ${ }^{*} p<0.05$ compared with CYT. Statistically significant differences in mean values was determined by Tukey-Kramer post hoc tests when NF- $k B$ was stained in the nucleus it was classified as NF- $k B^{+}$and nuclei without NF- $k B$ were classified as NF$\mathrm{KB}^{-}$(Fig. 4a). Following addition of cytokines, NF- $\mathrm{KB}^{+}$ nuclei doubled to $41.3 \pm 13.5 \%$ when compared with control $(21.6 \% \pm 5.3 \%$, Fig. 4 b). Treatment with $0.5 \mu \mathrm{g} / \mathrm{ml}$ WA $\left(19.5 \pm 8.1 \% \mathrm{NF}-\mathrm{KB}^{+}\right)$returned NF- $\mathrm{kB}$ activation to control levels. Adding $1.0 \mu \mathrm{g} / \mathrm{ml} \mathrm{WA}$ to human islets exposed to the cytokine cocktail reduced NF- $\mathrm{KB}$ translocation fourfold $\left(10.0 \pm 4.1 \% \mathrm{NF}-\mathrm{KB}^{+}\right)$compared with cytokine treatment alone. There was a significant difference $(p<0.05)$ between the cytokine- and WA-treated groups.

Increased MCP-1, IP-10, iNOS, and TF production in human islets is reduced by WA We studied the inflammatory response in human islets by immunohistochemical staining for IP-10, MCP-1, iNOS, tissue factor (TF) and insulin to confirm inhibition by WA in beta cells. Staining and micrograph capture conditions (exposure time, etc.) for each treatment group

\section{a}
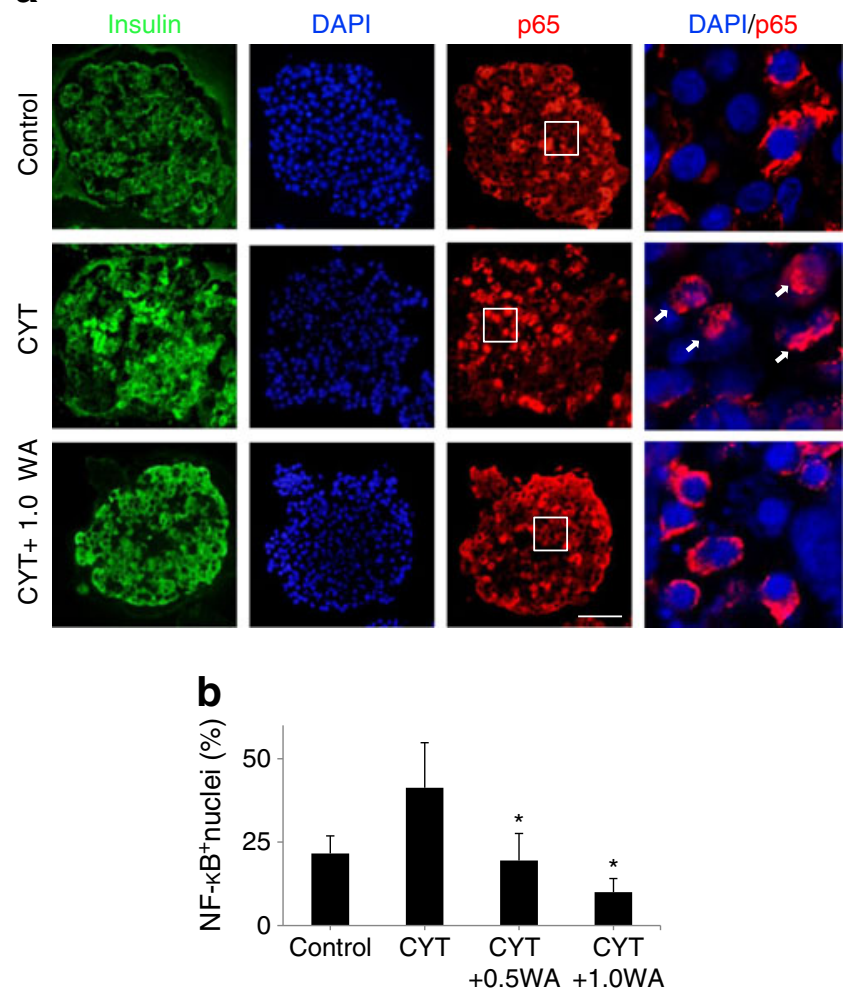

Fig. 4 NF- $\kappa B$ nuclear translocation is inhibited by WA. (a) Human islets were exposed to the cytokine cocktail (CYT) with or without $1.0 \mu \mathrm{g} / \mathrm{ml} \mathrm{WA}$ for $24 \mathrm{~h}$. Sections were stained for insulin (green), NFКB p65 (red) and for nuclei (blue). Merged nuclear and NF- $\mathrm{kB}$ staining revealed translocation with overlap of nuclei and p65 (indicated by white arrows). (b) Manual counting of at least 25 beta cell nuclei in ten islets for NF- $\mathrm{kB}$ translocation revealed that WA significantly inhibits $\mathrm{NF}-\mathrm{KB}$ activation down to control levels, and that $1.0 \mu \mathrm{g} / \mathrm{ml} \mathrm{WA}$ decreases NF- $\mathrm{KB}$ translocation to below control levels. Results shown are representative of three independent human islet preparations. Graphical representations are expressed as means \pm SD. ${ }^{*} p<0.05$ compared with CYT as determined by Tukey-Kramer post hoc tests 
were held constant, as described previously [26]. Treatment with cytokines for $48 \mathrm{~h}$ increased levels of MCP-1, IP-10, iNOS and TF (Fig. 5) in insulin-positive cells when compared with control islets, but these raised levels were significantly decreased by $0.5 \mu \mathrm{g} / \mathrm{ml} \mathrm{WA}$ in each case $(p<0.05)$.

To further support a direct role of NF- $\mathrm{KB}$ in preventing an inflammatory response in human islets, we used the highly selective inhibitor of IKK $\beta$, BMS-345541, in cytokine induction of inflammation-related genes [7]. In human islets, inflammatory genes (including those encoding TNF- $\alpha$, iNOS and IP-10) were all activated in response to cytokines (ESM Fig. 6). Induction of each of these genes was blocked in human islets when pretreated with BMS-345541. This data showed that although other signalling pathways are activated in islets by cytokines, NF- $\mathrm{KB}$ signalling is a requirement for activation of genes involved in inflammation.

Inflammatory cytokine and chemokine secretion by islets is inhibited by WA Previous studies have shown that NF- $\mathrm{kB}$ is implicated in the transcription of several inflammatory molecules [32-35]. These cytokines and chemokines also play a strong role in immune cell chemotaxis leading to poor engraftment. Cell culture supernatant fractions from human islets exposed to cytokines and WA $(0.5$ or $1.0 \mu \mathrm{g} / \mathrm{ml})$ were evaluated by a multiplex bead assay using xMAP technology ( $n=5$ independent experiments). IP-10 levels (Fig. 6a) were increased almost 6,000 -fold by cytokine treatment $(6,516 \pm 1,497.3 \mathrm{pg} /$ islet $)$ from control levels $(1.12 \pm$ $1.01 \mathrm{pg} /$ islet $)$. WA $(1.0 \mu \mathrm{g} / \mathrm{ml})$ decreased IP-10 to $2,915.3 \pm$ $356.1 \mathrm{pg} /$ islet in cytokine-treated islets. MCP-1, which is constitutively produced by islets [8], was marginally increased from $1,052.9 \pm 644.0 \mathrm{pg} /$ islet to $1,538.5 \pm 427.3 \mathrm{pg} /$ islet by cytokine treatment (Fig. 6b). WA treatment reduced MCP-1 levels to below control at $0.5(951.0 \pm 333.6 \mathrm{pg} /$ islet $)$ and $1.0 \mu \mathrm{g} / \mathrm{ml}(805.6 \pm 217.8 \mathrm{pg} /$ islet $)$ in cytokine-treated islets. Pro-inflammatory cytokines caused a six- to tenfold increase in islet basal levels of IL-6, IL-8, macrophage inflammatory protein (MIP)-1 $\alpha$, granulocyte-colony stimulating factor (G-CSF) (Fig. 6c-f), IL-1 $\alpha$ and MIP-1 $\beta$ (data not shown). Addition of WA led to a dose-dependent reduction in levels of these inflammatory molecules, with inhibition ranging from $71 \%$ to $88 \% ; 1.0 \mu \mathrm{g} / \mathrm{ml}$ WA significantly decreased the cytokine-stimulated levels $(p<0.05)$. This multiplex experiment was repeated with mouse islets, demonstrating dose-dependent inhibition of cytokine secretion (ESM Fig. 7).
Fig. 5 Inflammatory cytokine production and secretion from islets is decreased by WA treatment. (a) Human islets were exposed to the cytokine cocktail (CYT) with or without WA for $48 \mathrm{~h}$. Sections were probed for insulin (not shown), MCP-1 (top, red), IP-10 (second, red), iNOS (third, red), TF (bottom, red) and DNA (DAPI, blue). Intracellular staining revealed higher levels of MCP-1 (b), IP-10 (c), iNOS (d), and TF (e) in islets exposed to cytokines, whereas these levels were significantly decreased by adding $0.5 \mu \mathrm{g} / \mathrm{ml}$ WA. Graphical representations are expressed as averages of mean fluorescence intensity (MFI) as arbitrary units $(\mathrm{AU}) \pm \mathrm{SD} .{ }^{*} p<0.05$ compared with CYT as determined by Tukey-Kramer post hoc tests. Scale bar, $50 \mu \mathrm{m}$ a
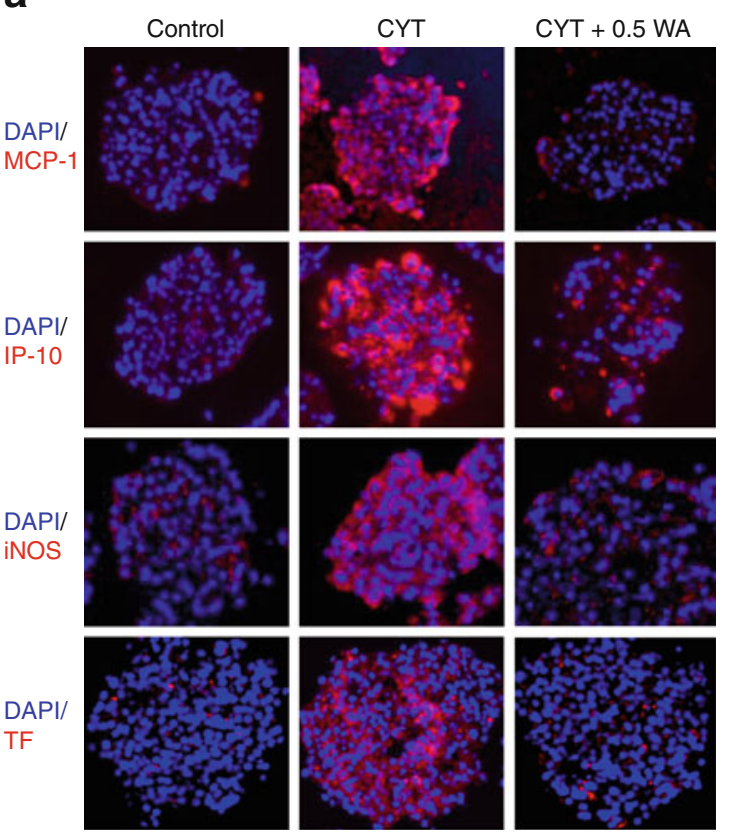

b

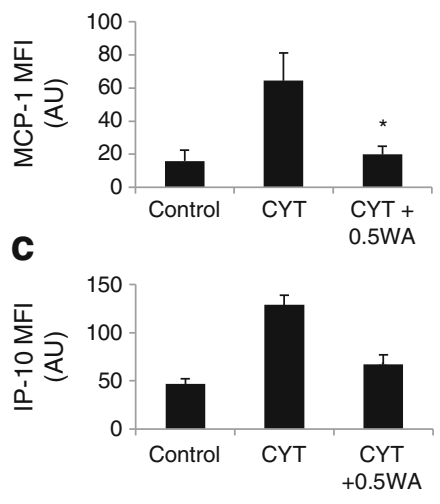

d
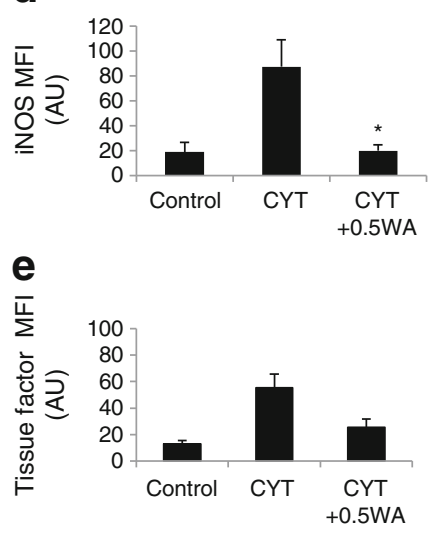

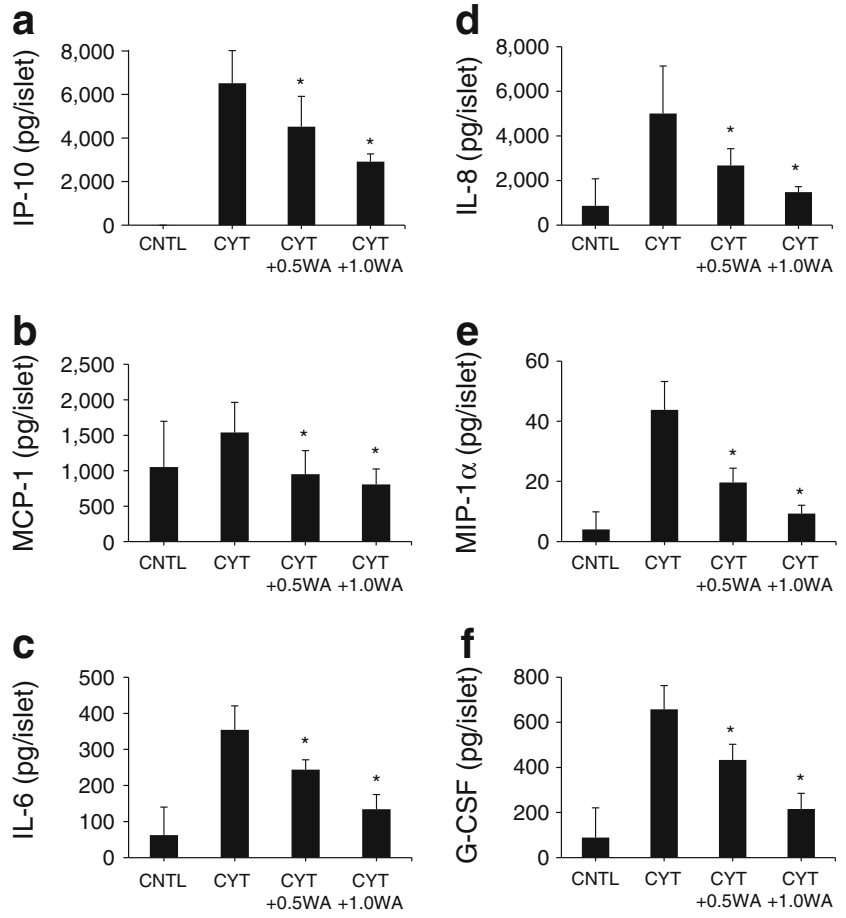

Fig. 6 WA inhibits a multitude of inflammatory cytokines and chemokines. Quintuplets of 50 handpicked human islets were cultured for $96 \mathrm{~h}$ with cytokines or cytokines supplemented with WA at $37^{\circ} \mathrm{C}$. The supernatant fraction was collected and analysed in duplicate with Millipore's human cytokine detection kit in the Luminex 200. Results were standardised to the number of islets. Results shown are representative of three independent human islet preparations. Graphical representations are expressed as means $\pm \mathrm{SD}$. ${ }^{*} p<0.05$ compared with CYT as determined by Tukey-Kramer post hoc tests

To test the inhibitory effect of WA on islets alone or other inflammatory cells, we tested human neutrophil infiltration into purified human islets using an in vitro model [31]. WA was added to either human blood alone or purified islets alone and subsequently islets and blood were mixed for analysis of neutrophil infiltration. Under both conditions, significant inhibition of neutrophil infiltration was observed (ESM Fig. 8) indicating that WA can inhibit IL-8 (neutrophil chemoattractant) in different cell types. Resveratrol, a known NF-kB blocker, was also tested in this experiment and showed weaker inhibition when compared with WA.

\section{Discussion}

One of the major hurdles to improving the current outcomes in clinical islet transplantation is the poor engraftment of transplanted islets. During the early post-transplant period, a major inflammatory response, termed IBMIR, which includes several pro-inflammatory cytokines, exerts a damaging effect on islets resulting in the loss of up to $75 \%$ of transplanted cell mass [36]. We attempted to abrogate the detrimental effects of pro-inflammatory cytokines using WA, which is known to influence several key signalling molecules including NF-KB [11]. Intraportal transplantation of syngeneic islets in diabetic C57BL/6 mice, a model representing inflammatory response to transplanted islets, showed that the engraftment of islets is significantly improved by WA. While several reports have shown that WA inhibits the NF-KB pathway through its binding to NEMO/ IKK $\beta$ complex $[14,15]$, no study has been undertaken on the use of WA to protect islets from inflammatory damage in islet transplants into diabetic mice. Despite significant work on islet reaction to inflammation, there has been little research into the contribution of islets to the immediate immune reaction. Hence we performed mechanistic studies to document inhibition of NF- $\mathrm{BB}$ and pro-inflammatory cytokines in human and mouse islets by WA. Activation of NF$\kappa \mathrm{B}$ in beta cells and islets by a cytokine cocktail was strongly inhibited by WA. This was demonstrated by the prevention of $\mathrm{I} \kappa \mathrm{B}$ degradation, NF- $\mathrm{KB}$ nuclear translocation and NF- $K B$ binding to DNA transcription sites as judged by p65 translocation, western blotting and DNA binding to a probe for the NF- $\mathrm{KB}$ consensus region of the iNOS promoter region. WA treatment led to significant inhibition of the production and secretion of inflammatory and chemotactic cytokines in islets as determined by immunohistochemistry and multiplex analysis. We have demonstrated that treatment with WA leads to significant improvement in islet survival and function in both human and mice islets under in vitro conditions. The in vitro results correlated with the in vivo data using the C57BL/6 mouse model showing improved achievement of normoglycaemia using marginal mass syngeneic islet transplants and inhibition of p65 translocation post-transplant.

Furthermore, we showed that induction of inflammatory cytokines, such as TNF $\alpha$, iNOS and IP-10, in human islets is significantly inhibited by the IKK $\beta$ specific inhibitor BMS-345541. These results indicate a prominent role for $\mathrm{NF}-\mathrm{KB}$ in cytokine-mediated damage to islets, which is prevented by WA. All of the human islet results corroborated the data from mouse islets indicating that WA has clinically relevant applications in humans. In fact two clinical trials have been reported using WA to treat anxiety disorder and osteoarthritis $[12,13]$ documenting the safety of its use in clinical settings.

Other studies have shown improvement of intraportal graft survival by NF- $\mathrm{KB}$ inhibition using a genetically enhanced, non-degradable IKB protein $[37,38]$ but this strategy is not easily applied to the clinical setting. A recent report by McCall et al [39] showed that resveratrol, another NF- $\kappa B$ inhibitor, failed to improve marginal mass engraftment of transplanted islets in mice. This report is in contrast to our current results and also data published by Chen et al [7], using BMS345541, which selectively blocks the IкB 
kinase subunit. This discrepancy could be due to specificity of the compounds in their inhibition of target proteins in the NF-KB pathway.

Previous studies have shown that WA can be used without causing damage to treated cells at concentrations similar to those used in this investigation [40, 41]. NF- $\mathrm{kB}$ translocation and inhibition data conformed to the results of cytokine studies of WA in pulmonary epithelial cells (A549) and cystic fibrotic KKLEB cells [16, 41]. Inactivation of protein kinase B (Akt) along with NF- $\mathrm{KB}$ inhibition murine macrophage cells has also been reported [42]. Effects on mitogenactivated kinases by WA were consistent with previous studies showing that, through the MAPK/ERK (MEK/ ERK) pathway, WA induces IKK $\beta$ phosphorylation with I $\mathrm{B}$ phosphorylation and degradation in mouse fibrosarcoma cells [14]. Secretion and localisation of chemokines, such as MCP-1, has been previously demonstrated in MCP-1 knockout mice and human studies [8,9]. However, MCP-1 is likely only one of many inflammatory molecules that contribute to immediate graft failure. Therefore, this study not only identifies additional cytokines and chemokines involved in inflammation (MCP-1, IP-10, IL-6, IL-8, G-CSF, MIP- $1 \alpha$, MIP- $1 \beta$ and IL- $1 \alpha$ ), but also demonstrates specific, potent inhibition of each by WA.

A recent study of an IKK- $\beta$ inhibitory agent found that the same set of cytokines did not affect cell death in islets under conditions favouring normal NF- $\mathrm{KB}$ activation but only under conditions of reduced NF- $\mathrm{KB}$ activation and hypoxia [7]. However, several other reports support our findings that cytokines cause cell death in islets and beta cells following activation of NF-kB [43]. Other reports concur with our findings that NF- $\mathrm{KB}$ inhibition prevents apoptosis and islet damage when islets are exposed to cytokines, using a degradation-resistant I $\mathrm{K} \mathrm{B} \alpha$ transgenic mouse and islet model $[37,44]$. Since NF- $\kappa B$ activation is involved in a broad range of biological processes, including cell survival, stress responses and maturation of various cell types, the present data is inadequate to confirm that NF$\mathrm{KB}$ inhibition alone is sufficient to protect islets from cytokine-induced apoptosis [45]. Oxygen free radicals (such as those produced from cytokine-stimulated iNOS) play a role in cytokine-mediated damage [46]. WA has been shown to exhibit antioxidant properties, which could protect islets from oxidative damage in addition to iNOS specific inhibition [11]. As there are many factors that potentially contribute to early graft loss, WA could have other effects that lead to graft survival (e.g. effects on TF levels, immune cell activation and neutrophil infiltration). Our preliminary findings indicate that WA can inhibit key aspects of IBMIR such as neutrophil infiltration [35] and TF expression.

The advantage of WA is that it could easily be incorporated into an immunosuppressive regimen for effective inhibition of inflammatory response. Recent clinical studies in islet transplantation have used etanercept, a soluble receptor antagonist to TNF- $\alpha$, alone [47] or in combination with anakinra (a soluble receptor antagonist to IL-1 $\beta$ [19]), to improve islet engraftment using marginal mass islet transplants. The improved outcome of clinical transplants with the combined use of etanercept and anakinra were further corroborated in marginal mass human islet transplants in immunodeficient mice [48]. Taken together, these reports emphasise the need to control inflammatory cytokines during the early transplant period to improve islet engraftment. The present study demonstrated that WA can profoundly inhibit the deleterious action of pro-inflammatory cytokines as well as the production of several chemotactic and inflammatory molecules by islets. Due to such protective effects, more islets could survive leading to euglycaemia in marginal islet infusions. The transplanted graft mass could be enhanced leading to prolonged insulin independence. This implication has significant ramifications for islet transplantation where it is often difficult to achieve sustained insulin independence with one donor pancreas.

Acknowledgements The authors thank A. Rahman and Y. Tamura (Baylor University Medical Center, Dallas, TX, USA) for their technical support for islet isolation and A. M. Brunsen (University of North Texas Health Science Center, Fort Worth, TX, USA) for her technical assistance with histology. Also the authors would like to thank S. Clayton for her expert technical advice on the use of laser scanning confocal microscope and M. Takita for editorial support (both at Baylor Research Institute, Dallas, TX, USA).

Funding This work was supported by a grant (No. 5-2010-668) from the Juvenile Diabetes Research Foundation (to B. Naziruddin) and also by the Baylor Health Care System. J. A. SoRelle is supported by a fellowship from Baylor University Institute of Biomedical Studies, Waco, TX, USA.

Duality of interest The authors declare that there is no duality of interest associated with this manuscript.

Contribution statement JAS wrote the manuscript and researched data. TI researched data, designed part of the study and contributed in equal amount to a majority of the research. MAK researched data and contributed to the discussion. KS researched data and provided aid with animal studies. HP researched data and contributed to the discussion. SM researched data and contributed to the discussion. MFL interpreted data. ML researched data and contributed to the discussion. BN contributed to the conception and design of the study and the discussion. All authors were involved in drafting or revision of the manuscript and gave final approval for submission.

\section{References}

1. Bennet W, Groth CG, Larsson R, Nilsson B, Korsgren O (2000) Isolated human islets trigger an instant blood mediated inflammatory reaction: implications for intraportal islet transplantation as a treatment for patients with type 1 diabetes. Ups J Med Sci 105:125-133

2. Bennet W, Sundberg B, Groth CG et al (1999) Incompatibility between human blood and isolated islets of Langerhans: a finding with implications for clinical intraportal islet transplantation? Diabetes 48:1907-1914 
3. Contreras JL, Eckstein C, Smyth CA et al (2004) Activated protein $\mathrm{C}$ preserves functional islet mass after intraportal transplantation: a novel link between endothelial cell activation, thrombosis, inflammation, and islet cell death. Diabetes 53:2804-2814

4. Amrani A, Verdaguer J, Thiessen S, Bou S, Santamaria P (2000) IL-1alpha, IL-1beta, and IFN-gamma mark beta cells for Fas dependent destruction by diabetogenic CD4 (+) T lymphocytes. J Clin Invest 105:459-468

5. Amoli MM, Bagher L (2005) Would blockage of cytokines improve the outcome of pancreatic islet transplantation? Med Hypotheses 66:816-819

6. Flodströma M, Welsh N, Eizirik DL (1996) Cytokines activate the nuclear factor $\mathrm{kB}(\mathrm{NF}-\mathrm{kB})$ and induce nitric oxide production in human pancreatic islets. FEBS Lett 385:4-6

7. Chen C, Moreno R, Samikannu B, Bretzel RG, Schumitz ML, Linn $T$ (2011) Improved intraportal islet transplantation outcome by systemic IKK-beta inhibition: NF-KB activity in pancreatic islets depends on oxygen availability. Am J Transplant 11:1-10

8. Peng H, Olsen GS, Tamura Y et al (2010) Inhibition of inflammatory cytokine-induced response in human islet cells by Withaferin A. Transplant Proc 42:2058-2061

9. Piemonti L, Leone BE, Nano R et al (2002) Human pancreatic islets produce and secrete MCP-1/ CCL2: relevance in human islet transplantation. Diabetes 51:55-65

10. Melzi R, Mercalli A, Sordi Vet al (2010) Role of CCL2/ MCP-1 in islet transplantation. Cell Transplant 19:1031-1046

11. Berghe WV, Sabbe L, Kaileh M, Haegeman G, Heyninek K (2012) Molecular insight in the multifunctional activities of Withaferin A. Biochem Pharmacol 84:1282-1291

12. Chopra A, Lavin P, Patwardhan B, Chitre D (2004) A 32-week randomized, placebo-controlled clinical evaluation of RA-11, an Ayurvedic drug, on osteoarthritis of the knees. J Clin Rheumatol 10:236-245

13. Cooley K, Szczurko O, Perri D et al (2009) Naturopathic care for anxiety: a randomized controlled trial ISRCTN78958974. PLoS One 3:e6628

14. Kaileh M, Berghe WV, Heyerick A et al (2007) Withaferin A strongly elicits IKB kinase $\beta$ Hyperphosphorylation concomitant with potent inhibition of its kinase activity. J Biol Chem 282:4253-4264

15. Grover A, Shandilya A, Punetha A, Bisaria VS, Sundar D (2010) Inhibition of the NEMO/IKK $\beta$ association complex formation, a novel mechanism associated with the NF-KB activation suppression by Withania somnifera's key metabolite Withaferin A. BMC Genom 11:S25

16. Maitra R, Porter MA, Huang S, Gilmour BP (2009) Inhibition of NF-kappaB by the natural product Withaferin $\mathrm{A}$ in cellular models of cystic fibrosis inflammation. J Inflamm (Lond) 13:15

17. Barnes PJ, Karin M (1996) NF-kB: a pivotal role in orchestrating chronic inflammation. N Engl J Med 336:1066-1071

18. Barnes PJ (1997) Molecules in focus nuclear factor-kB. Int $\mathbf{J}$ Biochem Cell Biol 29:867-870

19. Matsumoto S, Takita M, Chaussabel D et al (2011) Improving efficacy of clinical islet transplantation with iodixanol based islet purification, thymoglobulin induction and blockage of IL-1-beta and TNF-alpha. Cell Transplant 20:1641-1647

20. Takita M, Matsumoto S, Noguchi H et al (2010) One hundred human pancreatic islet isolations at Baylor Research Institute. Proc (Bayl Univ Med Cent) 23:341-348

21. Ricordi C, Lacy PE, Scharp DW (1989) Automated islet isolation from human pancreas. Diabetes 38(suppl 1):140-142

22. Matsuoka N, Itoh T, Watarai H et al (2010) High-mobility group box 1 is involved in the initial events of early loss of transplanted islets in mice. J Clin Invest 120:735-743
23. Itoh T, Sugimoto K, Shimoda M et al (2011) Establishment of a prolonged pancreas preservation model for islet isolation research in mice. Islets 3:376-380

24. Fornoni A, Pileggi A, Molano RD et al (2008) Inhibition of c-jun $\mathrm{N}$ terminal kinase (JNK) improves functional beta cell mass in human islets and leads to AKT and glycogen synthase kinase-3 (GSK-3) phosphorylation. Diabetologia 51:298-308

25. Delaney CA, Pavlovic D, Hoorens A, Pipeleers DG, Eizirik DL (1997) Cytokines induce deoxyribonucleic acid strand breaks and apoptosis in human pancreatic islet cells. Endocrinology 138:2610-2614

26. Huang D, Casale GP, Tian J (2007) Quantitative fluorescence imaging analysis for cancer biomarker discovery: application to beta-catenin in archived prostate samples. Canc Epidemiol Biomarkers Prev 16:1371-1381

27. Oyama K, Minami K, Ishizaki K, Fuse M, Miki T, Seino S (2006) Spontaneous recovery from hyperglycemia by regeneration of pancreatic $\beta$-cells in Kir6.2G132S transgenic mice. Diabetes 55:1930-1938

28. Hawiger J (2001) Innate immunity and inflammation: a transcriptional paradigm. Immunol Res 23:99-109

29. Hanada T, Yoshimura A (2002) Regulation of cytokine signaling and inflammation. Cytokine Growth Factor Rev 13:413-421

30. Karin M, Delhase M (2000) The I kappa B kinase (IKK) and NFkappa B: key elements of proinflammatory signaling. Semin Immunol 12:85-98

31. Kanak M, Iwahashi S, Itoh T et al (2012) Suppression of instant blood-mediated inflammatory reaction by NF-KB blockade. 2012 Rachmiel Levine Diabetes \& Obesity Symposium. (Abstract)

32. Hoffmann A, Levchenko A, Scott ML, Baltimore D (2002) The I $\kappa \mathrm{B}-\mathrm{NF}-\kappa \mathrm{B}$ signaling module: temporal control and selective gene activation. Science 298:1241-1245

33. Baeuerle PA, Baltimore D (1988) I kappa B: a specific inhibitor of the NF-kappa B transcription factor. Science 242:540-546

34. Parry GCN, Mackman N (1994) A set of inducible genes expressed by activated human monocytic and endothelial cells contain $\mathrm{kB}$-like sites that specifically bind c-Rel-p65 heterodimers. J Biol Chem 269:20823-20825

35. Baeuerle PA, Henkel T (1994) Function and activation of NF-kB in the immune system. Annu Rev Immunol 12:141-179

36. Piemonti L, Guidotti LG, Battaglia M (2010) Modulation of early inflammatory reactions to promote engraftment and function of transplanted pancreatic islets in autoimmune diabetes. In: Islam, MS (ed.) The islets of Langerhans. Advances in Experimental Medicine and Biology, Springer Netherlands, Heidelberg, Germany, pp 725-747

37. Rink J, Chen X, Xiaomin Z, Kaufman DB (2012) Conditional and specific inhibition of NF-KB in pancreatic $\beta$ cells prevents cytokine-induced deleterious effects and improves islet survival post transplant. Surgery 151:330-339

38. Heimber H, Heremans $Y$, Jobin $C$ et al (2001) Inhibition of cytokine-induced NF- $\mathrm{KB}$ activation by adenovirus-mediated expression of a NF- $\mathrm{kB}$ super-repressor prevents $\beta$-cell apoptosis. Diabetes 50:2219-2224

39. McCall MD, Pawlick R, Shapiro AM (2011) Resveratrol fails to improve marginal mass engraftment of transplanted islets of Langerhans in mice. Islets 3:241-245

40. Yu Y, Hamza A, Zhang T et al (2010) Withaferin A targets heat shock protein 90 in pancreatic cancer cells. Biochem Pharmacol 79:542-551

41. Oh JH, Kwon TK (2009) Withaferin A inhibits tumor necrosis factor- $\alpha$-induced expression of cell adhesion molecules by inactivation of Akt and NF-kB in human pulmonary epithelial cells. Int Immunopharmacol 9:614-619

42. Oh JH, Lett TJ, Park JW, Kwon TK (2008) Withaferin A inhibits iNOS expression and nitric oxide production by Akt inactivation 
and down-regulating LPS-induced activity of NF-kappaB in RAW 264.7 cells. Eur J Pharmacol 599:11-17

43. Melloul D (2008) Role of NF-kB in beta-cell death. Biochem Soc Trans 36:334-339

44. Ding X, Wang X, Xue W et al (2012) Blockade of the nuclear factor kappa B pathway prolonged islet allograft survival. Artif Organs 36:e21-e27

45. Shih VF, Tsui R, Caldwell A, Hoffman A (2011) A single NFkB system for both canonical and non-canonical signaling. Cell Res 21:86-102
46. Sumoski W, Baquerizo H, Rabinovitch A (1989) Oxygen free radical scavengers protect rat islet cells from damage by cytokines. Diabetologia 32:792-796

47. Hering BJ, Kandaswamy R, Ansite JD et al (2005) Single-donor, marginal-dose islet transplantation in patients with type 1 diabetes. JAMA 293:830-835

48. McCall M, Pawlick R, Kin T, Shapiro AM (2012) Anakinra potentiates the protective effects of etanercept in transplantation of marginal mass human islets in immunodeficient mice. Am J Transplant 12:322-329 